\title{
I-Level Predicates that Allow Existential Readings for Bare Plurals
}

\author{
Sheila Glasbey \\ Edinburgh University, Scotland, UK
}

\section{Individual-level predicates}

One of the defining characteristics of an individual-level (I-level) predicate is that it does not allow existential readings for bare plurals in subject position. (See, for example, (Carlson 1977, Kratzer 1988 and Diesing 1988.) Consider the following examples, where monkeys, students and dogs receive only the generic reading (roughly "all/most") in their respective sentences.

(1) Monkeys are mammals.

(2) Students are industrious.

(3) Dogs love meat.

(4) Students own sports cars.

The two main approaches in the literature to the analysis of bare plurals, those of Carlson and of Kratzer/Diesing ${ }^{1}$ are able to explain this observation, at least for bare plurals in subject position. ${ }^{2}$ Carlson 1977, for example, treats I-level predicates as predicates of kinds, leading to the prediction that bare plural subjects of I-level predicates will receive only generic readings. Note that in the Carlson and Kratzer/Diesing accounts, I-level predicates are identified, at least roughly, with permanent or near-permanent properties, although Carlson points out that this correspondence is not complete.

A number of exceptions have been observed to the generalization that Ilevel predicates allow only generic readings for their bare plural subjects (see, for example, Fernald 1994). It is not very difficult to think of further exceptions. Consider the following:

(5) Students own sports cars in this department.

The existential reading for students is readily available here. It is interesting to compare this with (4), where it is very difficult, if not impossible, to get the existential reading. Now consider:

(6) Monkeys live in trees.

where it is very difficult or impossible to get the existential reading for monkeys, and compare:

(C) 1997 by Sheila Glasbey Aaron Lawson (ed), SALT VII, 169-179, Ithaca, NY: Cornell University. 
(7) Monkeys live in that tree.

where it is not difficult to get an existential reading. (This example is taken from Fernald 1994.) And consider:

(8) Drinkers were under-age.

where it is difficult to get an existential reading, and compare:

(9) I was shocked to discover in the Red Lion last night that drinkers were under-age.

where the existential reading is readily available. Similarly, compare:

(10) Men are bald.

(existential reading very difficult or impossible)

(11) Men are bald as a result of using this brand of hair restorer.

(existential reading readily available).

Before considering what is responsible for the emergence of the existential reading in the second of each of these pairs of examples, let us check that the phenomenon is not a result of the predicates in question not being truly "permanent" or I-level. First, note that this would not explain the difference between the examples in each pair, given that the predicate is the same in each. Secondly, note that the effect is the same even when a predicate that is unarguably permanent is used.

(12) Ministers are gay.

(existential reading very difficult or impossible)

(13) In this church, ministers are gay.

(existential reading available). So we see that predicates for which this effect is observed do not correspond to "borderline" I-level predicates that have been "coerced" (to use Kratzer's term) to stage-level predicates (temporary properties).

What $i s$ going on here, then? We seem to have some kind of contextual effect. The extra context supplied by the second of each pair of sentences somehow makes available the existential reading for the subject bare plural. These "contextually-supplied" existential readings are not predicted by the classical accounts, and it is not at all obvious how to modify these accounts in order to explain these unexpected existential readings.

First, we need to be clear about exactly what kind of contextual effect is present. The effect has already been noticed by Fernald (1994), who calls it the 'definiteness effect', noting that the presence of definite NPs, as in (7), and other constructions such as PPs denoting specific locations, appear to make the existential reading easier to obtain. 
Fernald attempts to modify both the Carlson and Kratzer/Diesing accounts to accommodate the definiteness effect. He shows that this is an extremely difficult, if not impossible, task, particularly when one takes into account the extensive range of syntactic constructions that can have this effect.

Furthermore, as I will show below, the definiteness effect can be observed even in cases where there is no explicit syntactic construction giving rise to it. My examples below show that discourse context alone may give rise to the conditions, whatever they are, that allow existential readings to emerge for bare plural subjects of I-level predicates. Consider the following:

(14) John was shocked by his visit to the Red Lion. Drinkers were under-age, drugs were on sale, and a number of fights broke out while he was there.

In this discourse, the first sentence is responsible for establishing the "definiteness" (which I prefer to call the "situatedness"- - see below) of the scenario described in the following sentence (where we can get an existential reading for drinkers). That is, there is no syntactic element of the second sentence which can be said to be responsible for enabling the existential reading.

It is difficult to see how the Carlson and Kratzer/Diesing accounts could be modified, along the lines suggested by Fernald or indeed along any other lines, to account for a purely contextual effect like this.

In this paper I propose an analysis which accounts for such discourse context effects on the availability of existential readings for bare plural subjects of I-level predicates. My account is based on a modified version of Glasbey 1995 and Glasbey 1996. These papers give:

- A situation-theoretic analysis of bare plurals which accounts for the readings available for bare plurals in both subject and object positions;

- An account of the effect of context on existential readings for bare plural subjects of adjectival predicates.

I will begin by giving a short summary of the contents of these two papers, in order to familiarize the reader with the concepts and notation to be used in the analysis to follow. The interested reader should consult these papers for further details.

\section{Situation-Theoretic Account of Bare Plural Interpretation}

The situation-theoretic account of bare plural interpretation is based on the distinction between two kinds of predicate-relations and types-that can be made in situation theory (ST). I use the Extended Kamp Notation (EKN) of Barwise and Cooper 1993, and the version of situation theory defined in that paper.

Propositions in EKN include objects of the form: 


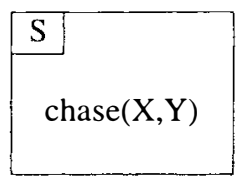

which is the proposition that a situation $S$ supports the infon $\operatorname{chase}(\mathrm{X}, \mathrm{Y})$. A proposition like this one is called an Austinian proposition. A second kind of situation theoretic proposition is exemplified by:

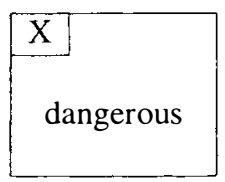

which is the proposition that an individual $\mathrm{X}$ is of the type dangerous. No situation is involved here. I call this a Russellian proposition. ${ }^{3}$

I propose that a certain class of predicates, roughly corresponding to the I-level predicates in the literature, correspond to ST types (and thus can form only Russellian propositions), while a second class of predicates (roughly corresponding to S-level ones) correspond to ST relations (and can form either Austinian propositions or Russellian ones). ${ }^{4}$

In addition, I take bare plurals to denote situation theoretic types. ${ }^{5}$

The non-generic reading (i.e., the "single event" reading) of:

(15) Dogs barked.

is represented as: ${ }^{6}$

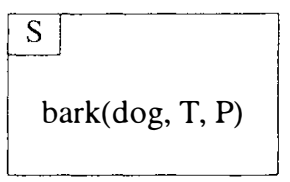

where dog is the type of dog objects. ${ }^{7}$

Thus the denotation of bare plurals differs from that of, say, proper names or pronouns, which are normally taken in situation theory to denote individuals.

Now compare:

(16) Hurricanes are dangerous.

which is taken to denote the truth of the proposition:

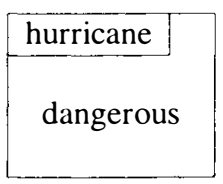


where hurricane is the type of hurricane objects. Further information can be derived from such a proposition. I show in Glasbey 1995 how we can use Channel Theory (Barwise and Seligman 1994) to express the information we can derive about the generic relation between being a hurricane and being dangerous.

Here, I concentrate on existential readings. Consider again the representation for the event reading of (15).

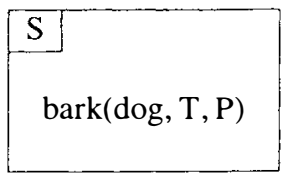

I propose that if a bare plural type is an argument of a relation, forming an infon which is supported by a situation, then an inference can be made to the effect that there are (at least two) instantiations of the bare plural type. Thus the truth of the above proposition allows us to infer that:

$\exists 2 X$ s.t.

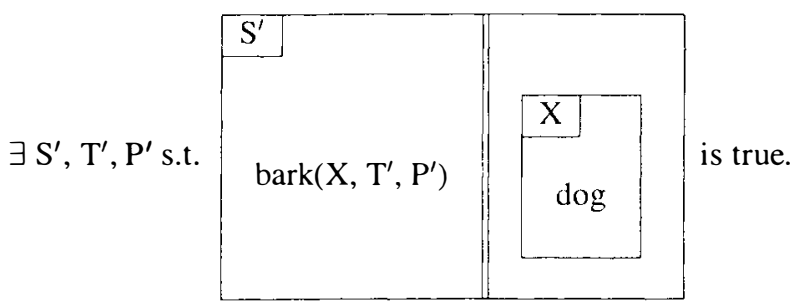

(Note that the proposition denoted here is a restricted proposition-the restriction being denoted by the inner box, to the right of the double line. The idea is that the entire restricted proposition only has a truth value if the restricting proposition,

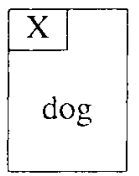

is true - otherwise it fails to denote.)

The inference is that there are at least two instances of $X$. That is, we infer that some (at least two) dogs barked. ${ }^{8}$

Thus the information about particular instances of the type dog and their participation in the relevant proposition is not information that is directly described by (15), but is, rather, information that is obtained indirectly by a process of inference. The fact that we infer the relation to hold of "some" rather than "all/most" dogs is a consequence of the fact that bark is a relation-the "situatedness" of the information is what leads to what I call the 'existential inference'. 
The account therefore predicts that existential readings will be available for bare plurals in a "situated" context-i.e., where the bare plural is an argument of a predicate that is a relation (and can thus participate in an Austinian proposition) as opposed to a type.

No existential reading is available for arguments of predicates that are types (such as dangerous, or the verbal like). The reason is that such predicates can only form Russellian propositions, of the form:

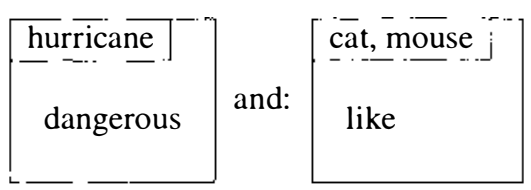

Here, because there is no situation, we cannot make the existential inference, and therefore we cannot get an existential interpretation for hurricanes, cats and mice respectively (the latter proposition is intended to correspond to the sentence Cats like mice).

\section{Adjectival S-level predicates-the missing readings}

The above account predicts (like Carlson and Kratzer/Diesing) that all Slevel predicates (both verbal and adjectival ones) will allow existential readings for their bare plural subjects. But there are many adjectival S-level predicates which do not allow existential readings at all easily, if at all. (This has been noted by Kiss 1994 and Greenberg 1994.) Consider, for example:

(17) Plates were dirty.

It is very difficult to get an existential reading for plates here. Now notice how things change if we add some discourse context:

(18) The hotel inspector filed a bad report on Fawlty Towers. The standard of service was, he said, disgraceful. Plates were dirty, cutlery was bent and floors were thick with grease.

(This example is based on one from Glasbey 1996.) And similarly, it is difficult to get an existential reading for children in:

(19) Children are sick.

Yet the existential reading is obtained without difficulty in:

(20) We must get a doctor. Children are sick.

Once again, the effect appears to the result of adding some context.

If we take these (S-level) predicates to be relations, as in Glasbey 1995, we need to explain, first of all, why the existential reading is not available in the 
first example of each pair, and then why it becomes available with the addition of a suitable context, as provided by (18) and (20).

The explanation given in Glasbey 1996 goes briefly as follows.

We saw above that the existential inference (which is what makes possible the existential reading) is licensed by presence of a situation supporting the relevant infon. For example, in:

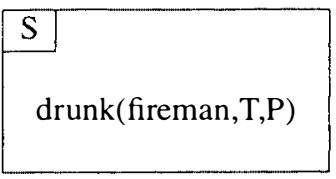

we make the existential inference concerning the existence of at least two firemen who were/are drunk, licensed by the presence of a situation $S$.

Now, suppose that only certain contexts can supply a situation to support the infon. Without such a situation, there can be no existential inference, and thus no existential reading. Suppose we then say that in an "empty context" there is no contextually-supplied situation available to support the infon. On the other hand, in cases like (18) and (20) where a context is provided, the contextual, descriptive, scene-setting material has the effect of providing an appropriate situation to support the infon. Hence in these cases we may make the existential inference, and the existential reading becomes available.

Thus the context may be seen as having a kind of situating effect-which consists of providing an appropriate situation. This situation is what enables the existential inference and thus licenses the existential reading. ${ }^{10}$

We now have to answer the question of why verbal S-level predicates behave differently from adjectival S-level predicates-why the former always appear to allow existential readings, whatever the context or lack of it. I propose that this is because a verbal S-level predicate always introduces a situation, thus allowing the existential inference, irrespective of context.

Why do verbal S-level predicates introduce their own situations? My explanation requires me to associate verbal relations with "events" (in the Davidsonian sense), in a way which we do not want to for adjectival relations. There seems to be something intuitively acceptable about this. For example, we might well want to say that:

\section{(21) Fido barked.}

introduces (or, at least, can do) a new event into the discourse context, while:

Fido was hungry.

can be seen as adding more information about an event or situation already present in the discourse context (see Glasbey 1994 for further discussion). If we think of an event as a (certain kind of) situation, we can say that a verbal relation always has the potential to introduce a new situation into the context. (In ST terms, we 
can identify this as the "minimal situation" or smallest situation supporting the relevant infon. See Cooper 1985 and Glasbey 1994 for discussion of minimal situations.)

Because adjectival relations do not introduce new events/situations into the context, they don't automatically give existential readings in the way that verbal relations do. In this case something else (that is, context) is needed to introduce the required situation.

\section{I-level predicates with existential readings}

Now we can return to the question with which we began this paper-why do many I-level predicates allow existential readings for their bare plural subjects if (and only if) a certain kind of discourse context is supplied?

To answer this, I modify the analysis of Glasbey 1995 and rather than classifying I-level predicates as types, now propose to classify them as relations which do not supply an event argument. This classification applies to both verbal and adjectival I-level predicates.

We can now say, just as we did for the adjectival S-level predicates, that an existential reading is available for bare plural subjects of I-level predicates iff the context supplies a suitable situation to support the relevant infon. Otherwise, only the generic reading is possible. This explains the observations with which we began - that is, the context-dependence of the availability of existential readings for bare plural subjects of I-level predicates.

\section{Conclusion}

To sum up: I propose that all I-level predicates, both verbal and adjectival ones, correspond to situation-theoretic relations which do not supply their own event/situation argument. This means that existential readings are available for the bare plural subjects of these predicates only in case the discourse context provides a suitable situation to support the infon in question. If this is the case, then the existential reading is available. If there is no context-supplied situation, then there is no existential reading. Thus the context-dependence of existential readings for I-level predicates is accounted for.

S-level predicates similarly correspond to relations, but they are divided into two classes: first, verbal S-level predicates, which supply their own situation (or "Davidsonian event argument") and hence always allow an existential reading, and second, adjectival S-level predicates, which do not (with a few exceptions) supply their own situation, and which therefore require the presence of a contextually-supplied situation to license the existential reading.

I have thus accounted for the observations with which we began-the "unexpected" existential readings for bare plural subjects of I-level predicates in certain contexts-which previous accounts have not been able to explain.

An important question that remains is that of whether there are any predicates which never allow an existential reading for their bare plural subjects, no 
matter what context is provided. If such predicates exist, then we may well wish to classify them as ST types rather than relations. I have not yet come across any such predicates, but clearly this question cannot be answered until a much more thorough search has been conducted.

\section{Notes}

${ }^{*}$ I would like to thank the participants of Salt VII for their helpful questions and comments following the presentation of this paper. I am also grateful to a number of colleagues who commented on this work and earlier versions of it. They include Nicholas Asher, Robin Cooper, Manfred Krifka and Carlota Smith. The work was supported in the main by an EPSRC postdoctoral fellowship.

${ }^{1}$ Although these latter two authors present distinct accounts, they have much in common and share many assumptions, and I will consider them together for the purposes of this paper.

${ }^{2}$ Predicting the readings for bare plurals in object position has proved rather more difficult. See, for example, (Kratzer 1988) and (Glasbey 1995) for discussion.

${ }^{3} \mathrm{My}$ use of the term 'Russellian' is slightly different from that of Barwise 1989, who uses it to refer to a proposition that a situation supports an infon, where the situation is existentially quantified.

${ }^{4}$ This idea is based on a proposal by Robin Cooper (p.c.), which was in turn inspired by Ladusaw 1994.

${ }^{5}$ See McNally 1995 for an independent but closely-related proposal that bare plurals in Spanish should be taken to refer to properties.

${ }^{6}$ I ignore tense here, for simplicity. I assume that relations have time (T) and place $(\mathrm{P})$ argument roles (which need not necessarily be filled in the syntax). See Glasbey 1994, ch.3 for discussion.

${ }^{7}$ Thus a relation like bark or chase, for example, can take either a parameter corresponding to an individual, or a type, as an argument.

${ }^{8}$ It appears that $S$ and $S^{\prime}$ may be different situations, though it seems clear that they must be, in some sense, closely related, as must $\mathrm{T}$ and $\mathrm{T}^{\prime}$, and $\mathrm{P}$ and $\mathrm{P}^{\prime}$. Further work is needed to determine exactly how they are related. Note that $S^{\prime}, T^{\prime}$ and $\mathrm{P}^{\prime}$ for the different $\mathrm{Xs}$ need not necessarily be distinct. There are interesting issues here regarding the distinction between distributive and collective predicates, which need to be explored further. Here, I make the simplifying assumption that 
the predicate is distributive.

${ }^{9}$ My proposal is clearly related to Carlson's (1977) idea that an SLP selects the "stage reading" of a kind-my notion of the existential inference being quite similar to the idea that bark selects a stage of the kind dogs. Perhaps my account of bare plurals can be viewed in a certain light as a reworking of Carlson's, within a situation theoretic framework, although of course I differ from him in not using stages.

${ }^{10}$ There are a few adjectival S-level predicates - including present and availablewhich appear to allow existential readings irrespective of context. The account in Glasbey 1996 offers an explanation for these.

\section{References}

Barwise, J. (1989). The Situation in Logic. Number 17 in CSLI Lecture Notes. Center for the Study of Language and Information, Stanford, Ca.

Barwise, J. and Cooper, R. (1993). Extended Kamp Notation: A graphical notation for situation theory. In Aczel, P., Israel, D., Katagiri, Y., and Peters, S., editors, Situation Theory and its Applications, volume 3 of CSLI Lecture Notes, chapter 2, pages 29-53. Center for the Study of Language and Information, Stanford, Ca.

Barwise, J. and Seligman, J. (1994). The rights and wrongs of natural regularity. In Tomberlin, J., editor, Philosophical Perspectives, volume 8, pages 331-365. Ridgeview, California.

Carlson, G. (1977). Reference to Kinds in English. PhD thesis, University of Massachusetts, Amherst.

Cooper, R. (1985). Aspectual classes in situation semantics. Report CSLI-84-14C, Center for the Study of Language and Information, Stanford, Ca.

Diesing, M. (1988). Bare plural subjects and the stage/individual contrast. In Krifka, M., editor, Genericity in Natural Language: Proceedings of the 1988 Tübingen Conference, pages 107-154. Seminar für Natürlich-Sprachliche Systeme, University of Tübingen, Germany. Report SNS-Bericht 88-42.

Fernald, T. B. (1994). On the Nonuniformity of the Individual-and Stage-Level Effects. PhD thesis, University of California, Santa Cruz.

Glasbey, S. (1994). Event Structure in Natural Language Discourse. PhD thesis, University of Edinburgh. 
Glasbey, S. (1995). A situation theoretic interpretation of bare plurals. Centre for Cognitive Science, University of Edinburgh. Paper presented at the Tbilisi Symposium, October 1995. To appear in the selected Proceedings.

Glasbey, S. (1996). Bare plurals, situations and discourse context. Centre for Cognitive Science, University of Edinburgh. Presented at the Second Conference on Information-Theoretic Approaches to Logic, Language and Computation, Regent's College, London, July 1996. To appear in the selected proceedings.

Greenberg, Y. (1994). Hebrew nominal sentences and the stage/individual level distinction. Master's thesis, Bar Ilan University, Israel.

Kiss, K. É. (1994). Generic and existential bare plurals and the classification of predicates. In Working Papers in the Theory of Grammar, volume 1 of Theoretical Linguistics Programme. Budapest University (ELTE), Budapest.

Kratzer, A. (1988). Stage-level and individual-level predicates. In Krifka, M., editor, Genericity in Natural Language: Proceedings of the 1988 Tübingen Conference, pages 247-284. Seminar für Natürlich-Sprachliche Systeme, University of Tübingen, Germany. Report SNS-Bericht 88-42.

Ladusaw, W. (1994). Thetic and categorical, stage and individual, weak and strong. In Harvey, M. and Santelmann, L., editors, Proceedings of SALT IV, pages 220-229, Ithaca, New York. Cornell University DMLL.

McNally, L. (1995). Bare plurals in Spanish are interpreted as properties. Unpublished ms, Universitat Pompeu Fabra, Spain. 